\title{
Fruits and vegetables and renal cell carcinoma: Findings from the European Prospective Investigation into Cancer and Nutrition (EPIC)
}

\author{
Steffen Weikert ${ }^{1,2}$, Heiner Boeing ${ }^{1 *}$, Tobias Pischon ${ }^{1,3}$, Anja Olsen ${ }^{4}$, Anne Tjonneland ${ }^{4}$, Kim Overvad ${ }^{5}$, Nikolaus Becker ${ }^{6}$, \\ Jacob Linseisen ${ }^{6}$, Petra H. Lahmann ${ }^{1}$, Athina Arvaniti ${ }^{7}$, Christina Kassapa ${ }^{7}$, Antonia Trichoupoulou ${ }^{7}$, Sabina Sieri ${ }^{8}$, \\ Domenico Palli ${ }^{9}$, Rosario Tumino ${ }^{10}$, Paolo Vineis ${ }^{11}$, Salvatore Panico ${ }^{12}$, Carla H. van Gils ${ }^{13}$, Petra H. M. Peeters ${ }^{13}$, \\ H. Bas Bueno-de-Mesquita ${ }^{14}$, Frederike L. Büchner ${ }^{14}$, Börje Ljungberg ${ }^{15}$, Göran Hallmans ${ }^{16}$, Göran Berglund ${ }^{17}$, \\ Elisabet Wirfält $^{17}$, Guillem Pera ${ }^{18}$, Miren Dorronsoro ${ }^{19}$, Aurelio Barricarte Gurrea ${ }^{20}$, Carmen Navarro ${ }^{21}$, \\ Carmen Martinez ${ }^{22}$, J. Ramón Quirós ${ }^{23}$, Naomi Allen ${ }^{24}$, Andrew Roddam ${ }^{24}$, Sheila Bingham ${ }^{25}$, Mazda Jenab ${ }^{26}$, \\ Nadia Slimani $^{26}$, Teresa Norat ${ }^{26}$ and Elio Riboli ${ }^{26}$ \\ ${ }^{1}$ Department of Epidemiology, German Institute of Human Nutrition Potsdam-Rehbruecke, Nuthetal, Germany \\ ${ }^{2}$ Department of Urology, Charité - University Medicine Berlin, Campus Benjamin Franklin, Berlin, Germany \\ ${ }^{3}$ Institute of Social Medicine, Epidemiology, and Health Economics, Charité-University Medicine Berlin, Berlin, Germany \\ ${ }^{4}$ Danish Cancer Society, Institute of Cancer Epidemiology, Copenhagen, Denmark \\ ${ }^{5}$ Department of Clinical Epidemiology, Aalborg Hospital, Aarhus University Hospital, Aalborg, Denmark \\ ${ }^{6}$ Division of Clinical Epidemiology, German Cancer Research Center, Heidelberg, Germany \\ ${ }^{7}$ Department of Hygiene and Epidemiology, School of Medicine, University of Athens, Athens, Greece \\ ${ }^{8}$ Epidemiology Unit, National Cancer Institute, Milan, Italy \\ ${ }^{9}$ Molecular and Nutritional Epidemiology Unit, CSPO-Scientific Institute of Tuscany, Florence, Italy \\ ${ }^{10}$ Cancer Registry, Azienda Ospedaliera "Civile M.P.Arezzo", Ragusa, Italy \\ ${ }^{11}$ University of Torino, Turin, Italy \\ ${ }^{12}$ Dipartimento di Medicina Clinica e Sperimentale, Università di Napoli Federico II, Naples, Italy \\ ${ }^{13}$ Julius Center for Health Sciences and Primary Care, University Medical Center Utrecht, Utrecht, The Netherlands \\ ${ }^{14}$ Netherlands National Institute for Public Health and the Environment, Centre for Nutrition and Health, Bilthoven, The Netherlands \\ ${ }^{15}$ Department of Surgical and Perioperative Sciences, Urology and andrology, Umea University, Umeå, Sweden \\ ${ }^{16}$ Department of Public Health and Clinical Medicine, Nutritional Research, Umeå University, Umeå, Sweden \\ ${ }^{17}$ Department of Medicine, Lund University, Malmö, Sweden \\ ${ }^{18}$ Department of Epidemiology, Catalan Institute of Oncology, Barcelona, Spain \\ ${ }^{19}$ Department of Public Health of Guipuzcoa, San Sebastian, Spain \\ ${ }^{20}$ Sección de Vigilancia y Control Epidemiologico, Instituto de Salud Publica de Navarra, Pamplona, Spain \\ ${ }^{21}$ Jefa de Servicio de Epidemiología, Consejería de Sanidad, Murcia, Spain \\ ${ }^{22}$ Escuela Andaluza de Salud Publica, Granada, Spain \\ ${ }^{23}$ Health Information Unit, Public Health and Health Planning Directorate, Asturias, Spain \\ ${ }^{24}$ Cancer Research UK Epidemiology Unit, University of Oxford, Oxford, United Kingdom \\ ${ }^{25}$ Dunn Human Nutrition Unit, Medical Research Council, Cambridge, United Kingdom \\ ${ }^{26}$ Nutrition and Hormones Group, IARC-WHO, Lyon, France
}

We examined the association between fruits and vegetables and risk of renal cell carcinoma (RCC) in the European Prospective Investigation into Cancer and Nutrition (EPIC). Dietary intake data and complete follow-up information on cancer incidence were available for 375,851 participants recruited in EPIC centers of 8 countries. During an average follow-up of 6.2 years, 306 incident cases of RCC were identified. The associations of consumption of total vegetables, total fruits, combined total fruits and vegetables and specific subtypes of vegetables with RCC risk were analyzed using Cox proportional hazards, stratified by centre and adjusted for potential confounders. No significant associations between fruit and vegetable consumption and RCC risk were observed despite a wide range of intake. The estimated relative risks $(95 \%$ confidence intervals $[\mathrm{CI}])$ in men and women combined were $0.97(0.85-1.11)$ per $40 \mathrm{~g}$ increase in vegetable intake, $1.03(0.97-1.08)$ per $40 \mathrm{~g}$ increase in fruit intake and $1.02(0.93-$ 1.11) per $80 \mathrm{~g}$ increase in fruit and vegetable intake combined. Among the vegetable subtypes, an inverse association was observed for root vegetables (RR per $8 \mathrm{~g}$ increase: 0.88 ; $95 \% \mathrm{CI}$ : $0.78-0.99)$. These results suggest that total consumption of fruits and vegetables is not related to risk of RCC, although we cannot exclude the possibility that very low consumption is related to higher risk. The relationship of specific fruit and vegetable subgroups with RCC risk warrant further investigation. (c) 2006 Wiley-Liss, Inc.

Key words: cohort study; epidemiology; food; incidence; kidney cancer

With its incidence continuing to increase, ${ }^{1}$ kidney cancer is today the fifth and the eleventh most common neoplasm in men and women in developed countries (http://www-dep.iarc.fr/). ${ }^{2}$ Renal cell carcinoma (RCC) accounts for more than $80 \%$ of all kidney cancers in adults. ${ }^{3}$ Although the proportion of incidentally diagnosed, asymptomatic RCC is increasing due to improvements in diagnostic imaging, $\sim 30 \%$ of patients still present with meta-

Contract grant sponsors: "Europe Against Cancer" Programme of the European Commission (SANCO); Deutsche Krebshilfe; German Cancer Research Center; German Federal Ministry of Education and Research; Danish Cancer Society; Health Research Fund (FIS) of the Spanish Ministry of Health; the Spanish Regional Governments of Andalucia, Asturia, Basque Country, Murcia and Navarra; the ISCIII Red de Centro RCESP (C03/09); Cancer Research UK; Medical Research Council, UK; the Stroke Association, UK; British Heart Foundation; Department of Health, UK; Food Standards Agency, UK; the Wellcome Trust, UK; Greek Ministry of Health; Greek Ministry of Education; Italian Association for Research on Cancer; Italian National Research Council, Compagnia di San Paolo; Dutch Ministry of Public Health, Welfare and Sports; National Cancer Registry and the Regional Cancer Registries Amsterdam, East and Maastricht of the Netherlands; World Cancer Research Fund (WCRF); Swedish Cancer Society; Swedish Scientific Council; Regional Government of Skåne, Sweden.

*Correspondence to: Prof. Heiner Boeing, German Institute of Human Nutrition, Department of Epidemiology, Arthur-Scheunert-Allee 114-116, D-14558 Nuthetal, Germany. Fax: +49-33200-88-444 or +49 3084454448. E-mail: boeing@mail.dife.de

Received 29 September 2005; Accepted 14 November 2005

DOI $10.1002 /$ ijc. 21765

Published online 19 January 2006 in Wiley InterScience (www.interscience. wiley.com). 
static disease, which is largely resistant to available therapies. ${ }^{4}$ Thus, RCC continues to be a difficult malignancy to treat, and primary prevention emerges as an important strategy.

Although smoking and obesity are established risk factors, the etiology of RCC is largely unknown. Geographic variations in RCC incidence and mortality ${ }^{2}$ suggest a role for environmental factors, such as diet, in the etiology of this disease. Diets rich in fruits and vegetables contain putative anticarcinogenic and antimutagenic substances and have been recommended for preventing cancer. ${ }^{5}$ However, convincing evidence for a protective role of these dietary components in cancer development is lacking for most malignancies, including RCC. ${ }^{6}$ A number of case-control studies have reported an inverse association between intake of either fruits or vegetables and RCC risk, ${ }^{7-11}$ while some investigations failed to demonstrate any significant association. ${ }^{12-14}$ More importantly, data from prospective studies remain sparse and largely non-conclusive. ${ }^{15-18}$

The aim of our study was to examine the association of RCC incidence with fruit and vegetable consumption in the European Prospective Investigation into Cancer and Nutrition (EPIC). EPIC is a large cohort study including subjects from various geographic regions of Europe, thus spanning a wide range of different diets.

\section{Material and methods \\ Study population}

EPIC is a multi-center prospective cohort study designed to investigate the relationships between diet, lifestyle and environmental factors and the incidence of various types of cancer. The total cohort consists of 366,521 women and 153,457 men recruited in 23 centers in 10 European countries including Denmark, France, Germany, Greece, Italy, the Netherlands, Norway, Spain, Sweden and the United Kingdom. The participants included in this analysis were mostly aged between 25 and 70 years at time of enrolment (1992-1998) and recruited from the general population residing in defined geographic areas (i.e., town or province) in each of the 10 countries. Exceptions were the French cohort (based on female members of the health insurance for school employees), the Utrecht cohort in the Netherlands (based on women attending breast cancer screening), the Ragusa cohort in Italy (based on blood donors and their spouses) and the Oxford health conscious subcohort (recruited throughout the United Kingdom in order to enroll a large number of vegetarians and healthy eaters). Eligible subjects were invited to participate in the study, and those who accepted gave informed consent and completed questionnaires on their diet, lifestyle and medical history. Participants were predominantly of European origin. The methods have been described in full elsewhere. ${ }^{19,20}$

Subjects with missing questionnaire data or missing dates of diagnosis or follow-up, representing $2 \%$ of the participants, and those with prevalent cancer at any site at baseline examination were excluded for the present study. Further, individuals in the top and bottom $1 \%$ of the ratio of energy intake to estimated energy requirement (calculated from age, sex and body weight) were excluded to reduce the impact of implausible extreme dietary values on the analysis. According to these criteria, 480,871 participants were eligible for analysis. Additionally, we excluded the cohorts of Norway $(n=35,956)$ because of the short follow-up period and the French cohorts $(n=69,023)$ because of incomplete case identification procedures for this cancer site.

\section{Assessment of diet and lifestyle factors}

Diet was measured by country-specific validated food frequency questionnaires (FFQs) designed to capture local dietary habits and to provide high compliance. ${ }^{19,21}$ The questionnaires were self-administered in all centers except those in Greece, Spain and Ragusa/Italy, where participants were interviewed using a computerized dietary program. A questionnaire and a seven-day dietary record were adopted in the United Kingdom, and an inter- view based diet history method combining a questionnaire with a 7-day menu book was used in Malmö, Sweden. Participants were asked to report their average consumption of each food over the previous 12 months, according to pre-coded categories that varied from never or less than once per month to 6 or more times per day. The number of questions relating to specific fruit and vegetable intake varied in centers, broadly reflecting the usual variety of these foods available to participants.

To correct for estimation errors and optimize comparability of dietary data across all EPIC centers, intake data from the questionnaires were calibrated using a single 24-hr dietary recall (24-HDR) method common to all centers. ${ }^{22}$ These data were collected from an $8 \%$ sample of the entire EPIC cohort (36,900 individuals). Using these data, intakes estimated from the FFQ can be transformed to a common scale, enabling comparisons of cancer risk in relation to food intake to be made across all EPIC centers as a whole. The analyses conducted in our study included total fruits, total vegetables and total fruits and vegetables combined. In addition, the total vegetable consumption was subdivided into specific vegetable subgroups, ${ }^{23}$ including leafy vegetables, fruiting vegetables, root vegetables, onion and garlic and cabbages. Other subgroups accounted for very small proportions of total vegetable intake and have therefore not been considered for separate analyses.

Baseline information on lifestyle variables was obtained from standardized questionnaires including questions on education, socioeconomic status, medical history and consumption of tobacco and alcoholic beverages. Height and weight were measured at recruitment, except for subjects in the Oxford health conscious subcohort, among whom height and weight were self-reported.

\section{Assessment of endpoints}

Incident kidney cancer cases were identified by population cancer registries (Denmark, Italy, the Netherlands, Spain, Sweden, the United Kingdom) or by active follow-up (Germany, Greece), depending on the follow-up system in each of the participating countries. Active follow-up used a combination of methods, including health insurance records, cancer and pathology registries and direct contact of participants or next-of-kin. Mortality data were also obtained from cancer or mortality registries at the regional or national level. Participants were followed from study entry until date of kidney cancer diagnosis or censoring due to death, emigration, loss to follow-up or end of follow-up. Mortality data were coded following the rules of the 10th revision of the International Statistical Classification of Diseases, Injuries and Causes of Death (ICD-10) and cancer incidence data following the 2nd revision of the International Classification of Diseases for Oncology (ICD-O-2). By the end of May 2004, 347 kidney cancer cases eligible for analysis according to the aforementioned criteria had been included in the central EPIC database. After further excluding 41 subjects with cancers not classified as RCC, e.g. cancer of the renal pelvis, our final dataset for analysis included 306 cases of incident RCC among 375,851 participants.

\section{Statistical analyses}

The association between fruit and vegetable consumption and risk of RCC was analyzed by using Cox proportional hazard models with center as stratum variable to control for center effects related to differences in questionnaire design and follow-up procedures. Age was used as the underlying time variable in the counting process with entry time defined as the subject's age in days at recruitment and exit time defined as the subject's age in days at RCC diagnosis or censoring. Models were stratified by age at recruitment. In addition, the analyses were adjusted for estimated energy intake (continuous) divided into energy from fat and energy from non-fat sources, as fruit and vegetable intake largely contribute to the non-fat energy components of the diet. ${ }^{24,25}$ Models were further adjusted for body mass index (continuous), smoking status defined as never, former (quit $\geq 10 \mathrm{y}$ ago, $<10$ years ago or unknown), current $(<10,15-24, \geq 25$ cigarettes smoked per 
TABLE I - CHARACTERISTICS OF THE EPIC COHORT

\begin{tabular}{|c|c|c|c|c|c|c|c|c|c|}
\hline \multirow{2}{*}{ Center } & \multirow{2}{*}{ Cohort size } & \multirow{2}{*}{ Female $(\%)$} & \multirow{2}{*}{$\operatorname{Age}^{1}(y)$} & \multicolumn{2}{|c|}{ Person-years (PY) } & \multicolumn{2}{|c|}{ RCC cases $(n)$} & \multicolumn{2}{|c|}{ Incidence rate $^{2}$ per $10,000 \mathrm{PY}$} \\
\hline & & & & Men & Women & Men & Women & Crude & Age-standardized $^{3}$ \\
\hline Italy & 44,567 & 68.5 & $50(35-66)$ & 75,159 & 188,663 & 15 & 28 & 1.87 & 2.24 \\
\hline Spain & 40,000 & 62.1 & $49(35-65)$ & 103,703 & 163,958 & 17 & 7 & 1.22 & 1.29 \\
\hline UK & 75,140 & 69.4 & $49(21-77)$ & 121,285 & 284,572 & 25 & 13 & 1.33 & 1.38 \\
\hline Netherlands & 37,394 & 73.5 & $49(21-69)$ & 50,100 & 182,107 & 4 & 25 & 1.55 & 1.54 \\
\hline Greece & 25,571 & 58.6 & $53(29-76)$ & 39,012 & 55,813 & 3 & 3 & 0.90 & 0.57 \\
\hline Germany & 49,511 & 58.6 & $51(35-65)$ & 125,744 & 163,333 & 44 & 22 & 3.33 & 3.26 \\
\hline Sweden & 48,612 & 54.1 & $52(29-72)$ & 175,674 & 204,877 & 33 & 17 & 1.54 & 1.52 \\
\hline Denmark & 55,056 & 52.2 & $57(50-65)$ & 174,987 & 194,426 & 28 & 22 & 1.29 & 1.26 \\
\hline EPIC & 375,851 & 62.0 & $51(23-73)$ & 865,664 & $1,437,749$ & 169 & 137 & & \\
\hline
\end{tabular}

${ }^{1}$ Mean (1st and 99th percentiles).- ${ }^{2}$ Restricted to participants aged $\geq 50$ to $<70 \mathrm{y}$, as this range is common to all countries. $-{ }^{3}$ Direct standardization using the age distribution of the total EPIC population as the reference.

day or unknown), duration of smoking (continuous), educational attainment (none or primary school, technical/professional school, secondary school or university) and recent alcohol consumption (continuous).

The estimated fruit and vegetable intakes were expressed in grams per day and tested for their relationship to RCC risk on a continuous scale (increments: $80 \mathrm{~g} / \mathrm{d}$ for combined intake of fruits and vegetables representing one portion according to 5-a-day recommendations, $40 \mathrm{~g} / \mathrm{d}$ for total vegetables and total fruits, $8 \mathrm{~g} / \mathrm{d}$ for vegetable subgroups). The analyses were based on calibrated food intake information. The calibration method used has been previously described. ${ }^{22,26,27}$ Briefly, the food item specific 24-hr diet recall values were regressed on the respective dietary questionnaire values, stratified by sex. Center-specific regression calibration models were used to correct for bias mainly attributable to differences in the dietary assessment instruments among EPIC centers. Weight, height, age at recruitment as well as center and country were included as covariates in these models. To control for seasonal and day-of-the-week variations in dietary consumption, the results were weighted for day and season of the dietary recall interview. By using this linear regression calibration model, predicted values of fruit and vegetable intake were obtained for each individual. Participants who were non consumers, based on the information obtained from the dietary questionnaires, were excluded from the calibration models. These individuals were all given a predicted value of 0 . Cox regression models were applied using the predicted intake values for each individual. An indicator variable (1, non consumer; 0 , consumer) was included in the Cox regression.

Models were run separately for men and women and for both sexes combined. Potential gender specific differences in relative risk estimates were further evaluated by the respective interaction term. In additional analyses, we stratified by smoking status and BMI categories $(\leq 25 v s .>25)$ in order to detect potential differences in risk estimates between smokers and non-smokers as well as between overweight and non-overweight subjects. Further, interaction with smoking and BMI was analyzed. Smokers were defined as current smokers at baseline or former smokers who had quit less than 10 years before the baseline examination. Nonsmoker included never smokers and former smokers who had quit 10 or more years before baseline.

To further examine the dose-response pattern, we used linear and cubic spline regression including the full set of covariates in the regression models. Spline regression is a more flexible approach to investigate potential non-linearity of the relative risk function. $^{28,29}$ The following knots were used in this analysis: Total fruits and vegetables $(160,280,360,460$ and $600 \mathrm{~g} / \mathrm{d})$ fruits $(80$, 160, 200, 260 and $420 \mathrm{~g} / \mathrm{d})$; vegetables $(90,130,160,200$ and $240 \mathrm{~g} / \mathrm{d})$. Tests for non-linearity were performed using log-likelihood ratio tests of hierarchical models with and without inclusion of spline terms. Although the models were fit to all available data, we did not graph predictions from extreme intake values as splines are recognized to produce unstable estimates in the tails ${ }^{29,30}$ All analyses were run using the SAS Statistical Software, version 9.13. (SAS Institute, Cary, NC, USA). All $p$-values presented are 2 -sided, and those $<0.05$ were considered statistically significant.

\section{Results}

After an average follow-up of 6.2 years covering 2,303,413 person years, 306 cases of incident RCC were identified among the 375,851 participants (Table I). The mean age at diagnosis was 62 years. The observed incidence rates were relatively high in Germany and Italy, while low rates were noted in Greece and Spain. This pattern of incidence broadly reflects recent incidence data from the statistics of these countries reported to the IARC database (http://www-dep.iarc.fr/). Data on histopathologic subclassification of RCC are incomplete and have therefore not been included in this report. The mean BMI was 26.4 for men and 25.6 for women, with the centre-specific mean values being highest in Granada/Spain for both men (28.9) and women (29.0) and lowest in the Oxford health conscious cohort (24.0 and 23.3).

The sex-specific mean predicted intake of fruits and vegetables across EPIC centers is given in Figure 1. Fruits and vegetables were consumed in relatively high amounts in the Mediterranean cohorts, whereas low amounts of daily intake were seen in Swedish cohorts. The centre-specific means of combined fruit and vegetable intake varied by the factor 3.4 (men) and 2.4 (women) along a South-North gradient, with the highest value observed in Murcia/Spain and the lowest in Umea/Sweden. This South-North pattern was more pronounced for fruits than for vegetables and higher variability was reported for men than for women (Fig. 1). The characteristics of consumption by vegetable subtypes in EPIC have been published in detail elsewhere. ${ }^{23}$ Table II depicts selected baseline characteristics of the participants across categories of fruit and vegetable consumption.

Table III shows the estimated relative risks (RRs) of RCC per computed increments in mean daily intake of total consumption of fruits and vegetables (combined and each separate) and consumption of subgroups of vegetables. No association was observed between combined consumption of total fruits and total vegetables and risk of RCC in both women and men. Inverse associations were observed for consumption of root vegetables (i.e., beetroot, carrot, turnip, parsnip, celeriac, radish, horseradish, kohlrabi), being statistically significant in male participants and for both sexes combined. It must be kept in mind, however, that multiple between-group comparisons are reported here, which may inflate type I errors. No associations were observed for consumption of other vegetable subtypes. None of the tests for interaction of consumption of fruits and vegetables or vegetable subgroups with sex were significant at the $5 \%$-level.

Furthermore, we ran separate analyses for smokers and nonsmokers as well as for overweight and non-overweight participants. These stratum specific analyses did not appreciably change 


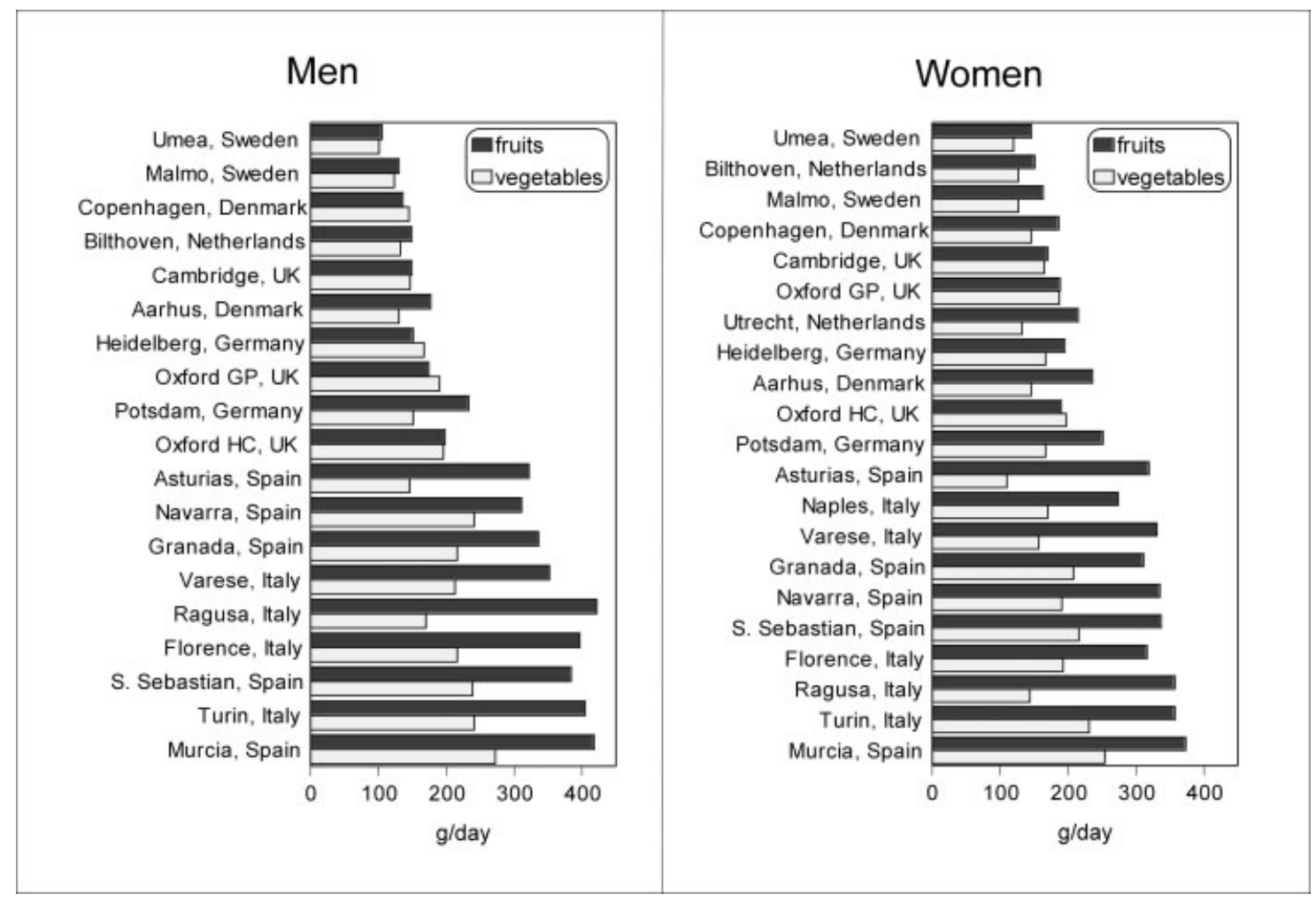

FIGURE 1 - Consumption of fruits and vegetables by participating EPIC center. The mean predicted daily intake (g/d) of total fruits and total vegetables is shown for men and women in 19 and 21 EPIC centers, respectively. Ranking of centers is based on combined fruit und vegetable intake. The highest combined intake was observed in Mediterranean cohorts (bottom), while low intake was reported in Northern European cohorts (top). Oxford GP, Oxford General Population; Oxford HC, Oxford Health Conscious.

TABLE II - COHORT CHARACTERISTICS ${ }^{1}$ BY CATEGORIES OF PREDICTED TOTAL FRUIT AND VEGETABLE CONSUMPTION

\begin{tabular}{|c|c|c|c|c|c|c|c|c|c|c|c|c|}
\hline & \multicolumn{7}{|c|}{ Fruit intake $(\mathrm{g} / \mathrm{d})$} & \multicolumn{5}{|c|}{ Vegetable intake $(\mathrm{g} / \mathrm{d})$} \\
\hline & $\leq 120$ & $121-160$ & $161-200$ & $201-240$ & $241-280$ & $281-320$ & $>320$ & $\leq 120$ & $121-160$ & $161-200$ & $201-240$ & $>240$ \\
\hline \multicolumn{13}{|l|}{ Total energy intake } \\
\hline From fat (kcal/d) & 873 & 786 & 766 & 760 & 756 & 754 & 796 & 831 & 793 & 753 & 770 & 868 \\
\hline From non-fat (kcal/d) & 1434 & 1321 & 1288 & 1265 & 1276 & 1321 & 1465 & 1358 & 1369 & 1318 & 1335 & 1418 \\
\hline BMI $\left(\mathrm{kg} / \mathrm{m}^{2}\right)$ & 25.6 & 25.3 & 25.5 & 26.0 & 26.3 & 26.4 & 26.6 & 25.5 & 25.8 & 25.8 & 26.2 & 27.1 \\
\hline Alcohol intake (g/d) & 16.7 & 12.4 & 11.3 & 10.7 & 11.0 & 11.4 & 13.3 & 11.1 & 13.3 & 12.3 & 12.7 & 16.2 \\
\hline Smoking, duration (y) & 17.6 & 13.8 & 12.3 & 11.7 & 11.8 & 12.1 & 12.3 & 16.8 & 14.5 & 11.0 & 10.9 & 14.5 \\
\hline \multicolumn{13}{|l|}{ Smoking, frequency $(\%)$} \\
\hline Never & 36.8 & 44.7 & 48.5 & 50.9 & 51.7 & 51.6 & 50.6 & 42.9 & 43.8 & 52.0 & 52.2 & 41.1 \\
\hline Former $\geq 10 \mathrm{y}$ & 21.1 & 23.8 & 23.9 & 22.7 & 21.0 & 20.8 & 22.6 & 20.2 & 24.5 & 22.6 & 20.8 & 22.6 \\
\hline$<10 \mathrm{y}$ & 4.8 & 4.6 & 4.0 & 3.9 & 3.7 & 3.8 & 4.1 & 3.7 & 3.9 & 4.0 & 4.4 & 6.3 \\
\hline Unknown & 2.1 & 1.8 & 1.8 & 1.5 & 1.2 & 1.0 & 0.9 & 1.5 & 2.0 & 1.5 & 0.9 & 0.8 \\
\hline Current $<15 \mathrm{cig} / \mathrm{d}$ & 13.1 & 11.3 & 10.2 & 9.9 & 10.7 & 12.0 & 11.5 & 13.7 & 11.6 & 9.8 & 10.3 & 12.0 \\
\hline $15-24 \mathrm{cig} / \mathrm{d}$ & 13.7 & 8.8 & 7.3 & 6.7 & 7.2 & 7.0 & 6.6 & 12.3 & 9.2 & 6.4 & 6.7 & 8.1 \\
\hline$\geq 25 \mathrm{cig} / \mathrm{d}$ & 5.2 & 2.8 & 2.5 & 2.7 & 2.8 & 2.7 & 2.4 & 3.5 & 2.9 & 2.2 & 2.8 & 6.7 \\
\hline Unknown & 2.3 & 1.3 & 0.9 & 0.7 & 0.5 & 0.4 & 0.5 & 1.5 & 1.3 & 0.8 & 0.7 & 0.4 \\
\hline Unknown & 1.1 & 0.8 & 1.0 & 1.1 & 1.1 & 0.8 & 0.9 & 0.8 & 0.9 & 0.7 & 1.3 & 2.0 \\
\hline \multicolumn{13}{|l|}{ Education, Frequency (\%) } \\
\hline Non, primary school & 27.0 & 24.5 & 25.2 & 31.0 & 34.7 & 36.5 & 38.8 & 36.7 & 28.2 & 25.7 & 30.3 & 39.8 \\
\hline Technical prof. school & 30.5 & 30.9 & 29.5 & 24.8 & 21.6 & 19.2 & 16.5 & 28.9 & 30.8 & 23.5 & 18.3 & 17.2 \\
\hline Secondary school & 16.9 & 14.0 & 13.3 & 15.1 & 17.9 & 22.0 & 24.9 & 17.8 & 16.0 & 16.9 & 20.8 & 19.1 \\
\hline University degree & 22.9 & 26.3 & 26.4 & 23.6 & 21.5 & 18.8 & 17.0 & 15.8 & 22.6 & 27.4 & 23.9 & 19.4 \\
\hline Male gender, Frequency (\%) & 61.5 & 35.2 & 28.6 & 26.8 & 26.1 & 27.3 & 42.8 & 42.2 & 39.3 & 30.1 & 32.6 & 56.6 \\
\hline
\end{tabular}

${ }^{1}$ For continuous variables values are expressed as mean; for categorical variables frequencies are given in percent.

the results for fruits and fruits and vegetables. No interactions with either smoking or BMI were observed $(p=0.567$ and 0.337 for fruits and vegetables; $p=0.401$ and 0.386 for fruits). For root vegetables, the RR $(95 \% \mathrm{CI})$ per $8 \mathrm{~g}$ increase for the continuous intake variable was $0.77(0.60-1.00)$ for smokers, but $0.93(0.82-$ 1.07) for non-smokers. For total vegetables and other vegetable subgroups, no differences in risk estimates related to smoking status were observed. Stratification by BMI categories $(\leq 25$ vs. $>25)$ showed a trend toward an inverse association of $\mathrm{RCC}$ risk with total vegetable consumption in non-overweight subjects (RR per $40 \mathrm{~g}$ increase: 0.85 ; 95\% CI: 0.66-1.09), but not in overweight participants (RR: 1.05; 95\% CI: 0.90-1.23). For root vegetables, a 
TABLE III - MULTIVARIATE ${ }^{1}$ HAZARD RATIOS (HR) AND 95\% CONFIDENCE INTERVALS (CI) FOR RCC PER INTAKE INCREMENTS OF PREDICTED CONSUMPTION OF FRUITS, VEGETABLES AND VEGETABLE SUBGROUPS

\begin{tabular}{cccc}
\hline \multicolumn{1}{c}{ Food (g/day) } & Men & Women & All \\
\hline Total fruits and vegetables (per 80 g) & $1.03(0.92-1.16)$ & $0.99(0.86-1.15)$ & $1.02(0.93-1.11)$ \\
Total fruits (per 40 g) & $1.03(0.96-1.10)$ & $1.02(0.93-1.12)$ & $1.03(0.97-1.08)$ \\
Total vegetables (per 40 g) & $1.03(0.85-1.24)$ & $0.91(0.74-1.11)$ & $0.97(0.85-1.11)$ \\
Fruiting vegetables (per 40 g) & $1.09(0.75-1.57)$ & $1.06(0.76-1.49)$ & $1.01(0.79-1.29)$ \\
Root vegetables (per 8 g) & $0.81(0.67-0.98)$ & $0.88(0.75-1.04)$ & $0.88(0.78-0.99)$ \\
Leafy vegetables (per 8 g) & $1.08(0.93-1.25)$ & $0.89(0.72-1.10)$ & $1.01(0.90-1.13)$ \\
Onion, Garlic (per 8 g) & $0.90(0.65-1.25)$ & $0.83(0.49-1.38)$ & $0.87(0.67-1.13)$ \\
Cabbages (per 8 g) & $0.98(0.82-1.19)$ & $0.98(0.81-1.18)$ & $0.99(0.87-1.13)$ \\
\hline
\end{tabular}

${ }^{1}$ Models were adjusted for age, center, BMI, energy from fat sources, energy from non-fat sources, education, smoking, alcohol drinking and non-consumer status.

Figure 2 - Risk estimates of renal cell carcinoma by predicted consumption of total vegetables using cubic spline and linear (dashed line) regression models. Models were adjusted for age, center, BMI, energy from fat sources, energy from non-fat sources, education, smoking, alcohol drinking and non-consumer status.

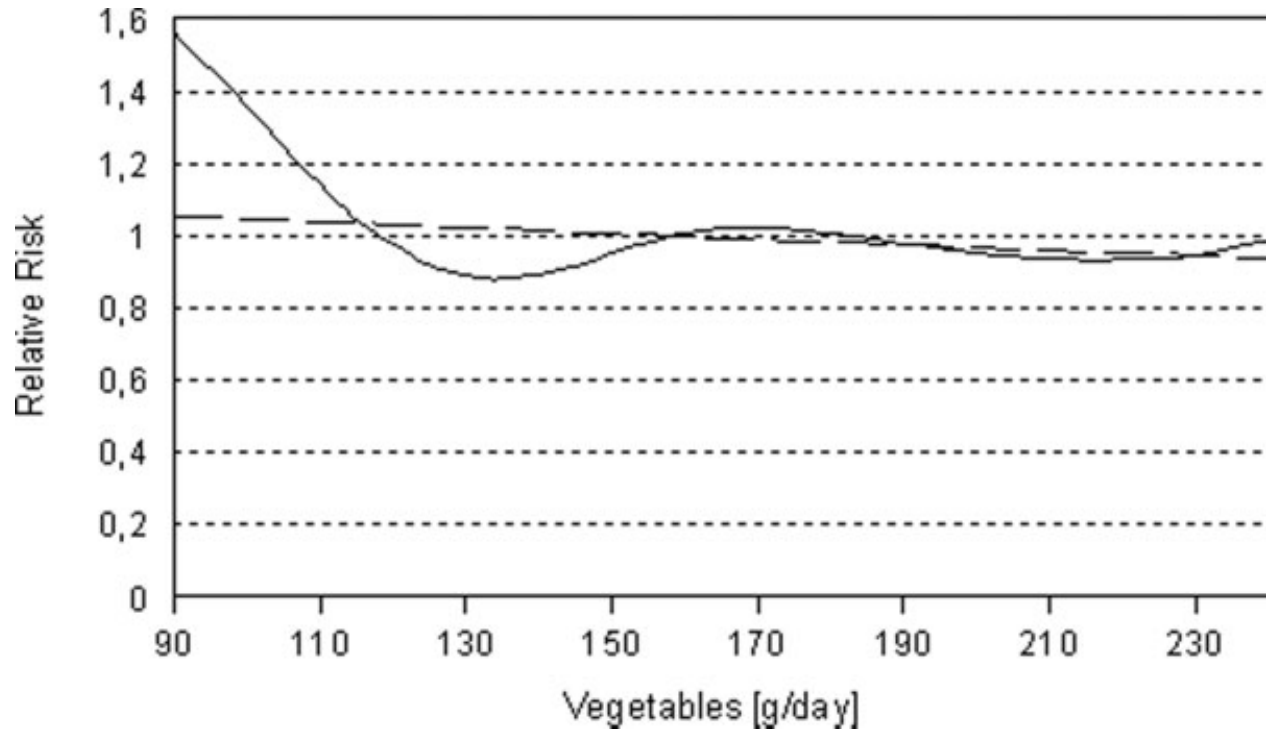

significant inverse association was restricted to non-overweight subjects (RR per $8 \mathrm{~g}$ increase: 0.76 ; 95\% CI: $0.60-0.96$ ), while no such association was seen in subjects with a BMI > 25 (RR: 0.94; 95\% CI: 0.82-1.07). Tests for interactions of total vegetable or root vegetable intakes with either smoking or BMI were not statistically significant $(p=0.961$ and 0.294 for total vegetables; $p=$ 0.283 and 0.984 for root vegetables).

In addition to the assessment of RCC risk related to the continuous intake variables using linear regression models, the relative risk functions were investigated by cubic spline regression. Although formal tests for non-linearity were nonsignificant $(p=$ 0.505 for fruits and vegetables, $p=0.273$ for fruits, $p=0.149$ for vegetables), the spline curve suggested an increase in the relative risks for renal cell cancer at very low vegetable consumption (between 90 and $130 \mathrm{~g} /$ day) (Fig. 2).

\section{Discussion}

In the European Prospective Investigation into Cancer and Nutrition, we observed no association between total consumption of fruits and vegetables and risk of RCC. This observation was independent of whether total intake was analyzed separately for fruits and vegetables or for both combined. In multiple exploratory analyses among subgroups of vegetables, consumption of root vegetables was inversely associated with the risk of RCC, while no such relationship was observed for other subgroups.

The present investigation is the largest prospective study in this field. Nevertheless, the number of RCC cases is still rather limited, which has to be kept in mind when interpreting the findings of the present investigation. On the other hand, the large population- based cohort and the fact that both female and male participants were studied are among the strengths of our study. Moreover, EPIC includes centers throughout Europe, covering a broad range of dietary habits. Compared to most other cohort studies on diet and cancer, EPIC covers a wide range of fruit and vegetable intake. ${ }^{23,31}$ Combined vegetables and fruit consumption varied 3fold along a South-North gradient, with the highest intake reported in Murcia/Spain and the lowest in Umea/Sweden. This South-North gradient was observed for both total vegetable and fruit consumption, but was not equally noted for all vegetable subtypes. While leafy and fruiting vegetable follow the general pattern, root vegetables and cabbages are consumed in comparatively higher amounts in Northern and Western European cohorts. Across country specific EPIC-centers, higher variation was noted for fruits than for vegetables. Given these characteristics of EPIC, it is unlikely that the absence of associations between RCC risk and fruits and vegetables was due to a reduced variability of intake, a problem that has been noted for cohort studies as a result of the higher likelihood of health-conscious subjects to participate. ${ }^{32,33}$ In this context, it is interesting to note that the risk of RCC slightly increased in subjects with very low vegetable consumption (between 90 and $130 \mathrm{~g} / \mathrm{d}$ ). Although formal tests for non-linearity were nonsignificant, we cannot exclude the possibility that very low vegetable consumption is related to increased RCC risk.

Besides the differences in dietary habits, cancer incidence rates show significant variability across countries of the EPIC-study (http://www-dep.iarc.fr/). ${ }^{2}$ The substantial overall heterogeneity of both the dietary exposure and RCC incidence across EPIC centers ${ }^{19}$ improves the power to detect potential associations between diet and cancer compared to other prospective studies and may strengthen the validity of our observations. Moreover, the combi- 
nation of 2 dietary intake assessments, FFQ and the 24-hr recall approach, minimizes the between-cohort differences due to systematic exposure measurement error and thereby increases true heterogeneity in dietary intake across centers. ${ }^{22,34}$ It was recently shown that, after considering within-centre attenuation effects, a substantial proportion of variation in consumption levels is explained by between-cohort differences. ${ }^{35}$ Nonetheless, the residual effects of measurement errors may lead to an attenuation of disease risk estimates. ${ }^{36}$ The applied linear regression calibration approach accounts for centre-specific measurement errors of the food frequency questionnaires and may thus strengthen relative risk estimates. A basic assumption of the calibration approach is that errors of the dietary questionnaires and those of the 24-hr recall are not correlated. However, this assumption may not be fully met in practice. ${ }^{36,37}$ As the hazard ratio estimates may thus be biased toward the null value, modest associations of fruit and vegetable consumption with $\mathrm{RCC}$ risk may not be detectable in our study. Moreover, the number of cases may still be too limited to provide sufficient statistical power for detecting a weak protective effect of fruit and vegetables on RCC development. The risk estimates obtained in our study are not adjusted for the potential risk factors hypertension ${ }^{38}$ and diabetes. ${ }^{39}$ It could be argued that residual confounding effects may have further attenuated the risk estimates toward the value of 1 if subjects with diabetes or hypertension were given advice to follow a healthy diet rich in fruits and vegetables. Alternatively, subjects with hypertension may be characterized by a diet low in fruits and vegetables, which theoretically could bias the estimates away from the null value of 1 .

Despite recognized limitations of our study, results are largely consistent with previous prospective investigations on $\mathrm{RCC}$ risk. To our knowledge, only 4 prospective cohort studies ${ }^{15-18}$ reporting data on fruit and vegetable consumption and risk of RCC have been published to date. In these studies, the number of incident cases were limited, ${ }^{15}$ or study populations were confined to postmenopausal women. ${ }^{16,17}$ A relatively small cohort study in California Seventh-day Adventists, who are largely non-smoking vegetarians, showed an inverse, albeit nonsignificant association between consumption of fruits and salad vegetables and RCC risk, but only 14 cases of RCC were identified among 34,198 participants. ${ }^{15}$ No association for total fruits and vegetables was observed in the Iowa Women's Health Study based on 124 cases of RCC among 34,637 postmenopausal women followed for 15 years. ${ }^{16}$ This confirmed the findings earlier reported on this cohort. ${ }^{40}$ Recently, a large cohort study in Swedish women ${ }^{17}$ reported evidence for an inverse association of fruit and vegetable intake with RCC risk yet still failed to demonstrate statistically significant relationships. A newly published Dutch case-cohort study including over 200 RCC cases observed null associations for fruit and vegetable consumption. ${ }^{18}$

The results from case-control studies have also been controversial. These studies have been reviewed in detail by an international expert committee. ${ }^{32}$ Among the several case-control studies, only $1^{9}$ reported a significant inverse association for both vegetable and fruit intake, while 2 studies observed a significant inverse association for either fruit ${ }^{7}$ or vegetable ${ }^{11}$ intake. Others observed inverse associations, ${ }^{8,10,41,42}$ but significant results were confined to male participants, ${ }^{8}$ non-smokers ${ }^{10}$ or consumption of specific subtypes of vegetables ${ }^{10,11}$ or fruits. ${ }^{41,42}$ No associations were found in 2 other studies. $^{13,14}$

Interestingly, we observed evidence for an inverse association of root vegetable consumption with RCC risk. However, it must be emphasized again, that the subgroup analyses are still based on a rather limited number of cases and must be interpreted cautiously because of multiple testing. Our results are in agreement with data recently reported from the Swedish mammography cohort. ${ }^{17}$ In that study, frequent consumption of root vegetable ( $\geq 1$ serving/d) compared to no consumption was associated with a significant $50 \%$ reduction in RCC risk (RR $0.49 ; 95 \%$ CI $=0.27$ $0.97 ; p=0.03)$. We are not aware of other studies that examined this subtype of vegetables for its association with RCC. Intake of yellow-orange vegetables that also include root vegetables (i.e., carrots) has been shown to be related to reduced risk for RCC. ${ }^{10,11}$

The possibility of an inverse association for root vegetables rather than all vegetables or fruits together leads to the question of which substances might be responsible for this relationship. Root vegetables include carrots with high contents of alpha- and betacarotene and other carotenoids. Carotenes are among the most effective antioxidants and are, therefore, thought to exhibit significant anticarcinogenic effects. ${ }^{5}$ However, studies analyzing the effect of carotene have not reported a significant association with RCC risk. ${ }^{10,12,42}$ The group of root vegetables also comprises certain cruciferous vegetables such as horseradish, radish, turnip and kohlrabi that contain considerable amounts of isothiocyanates and phenolics. These phytochemicals together with other constituents, i.e. dietary fiber, folic acid, selenium etc., are thought to exert anticancer activities by preventing DNA damage and increasing the cellular antioxidant capacity. ${ }^{43,44}$ The protective effects of a diet rich in fruits and vegetables seems to be the result of the complex mixture of several substances present in whole foods rather than due to any single nutrient or phytochemical. ${ }^{5,44}$ The data of the present study together with similar results published recently ${ }^{17}$ support further research into the biological mechanisms as well as potential response modifiers relevant for the effects of certain vegetables or fruits.

Taken together, the results available from EPIC so far do not support the hypothesis of an inverse association between dietary intake of fruits and vegetables and risk of RCC. However, the potential inverse association of total vegetable intake with RCC risk observed specifically at low intake warrants further investigation. In addition, high dietary intake of certain subtypes of vegetables or fruits, particularly root vegetables, may be capable of reducing the risk for RCC. In view of the still relatively short duration of follow-up, it can be expected that future analyses of RCC incidence in EPIC will be more informative after more years of follow-up.

\section{Acknowledgements}

The authors wish to thank all the participants in EPIC. They are also grateful to Wolfgang Bernigau for help in data management.

\section{References}

1. Mathew A, Devesa SS, Fraumeni JF, Jr, Chow WH. Global increases in kidney cancer incidence, 1973-1992. Eur J Cancer Prev 2002;11: 171-8.

2. Ferlay J, Bray F, Pisani P, Parkin DM. GLOBOCAN 2002: Cancer Incidence, Mortality and Prevalence Worlwide. Lyon: IARC Press, 2004.

3. Tavani A, La Vecchia C. Epidemiology of renal-cell carcinoma. J Nephrol 1997;10:93-106.

4. Martel CL, Lara PN. Renal cell carcinoma: current status and future directions. Crit Rev Oncol Hematol 2003;45:177-90.

5. Donaldson MS. Nutrition and cancer: a review of the evidence for an anti-cancer diet. Nutr J 2004;3:19.
6. Riboli E, Norat T. Epidemiologic evidence of the protective effect of fruit and vegetables on cancer risk. Am J Clin Nutr 2003;78(Suppl 3): S559-69.

7. Boeing H, Schlehofer B, Wahrendorf J. Diet, obesity and risk for renal cell carcinoma: results from a case control-study in Germany. Z Ernahrungswiss 1997;36:3-11.

8. McLaughlin JK, Gao YT, Gao RN, Zheng W, Ji BT, Blot WJ, Fraumeni JF, Jr. Risk factors for renal-cell cancer in Shanghai, China. Int J Cancer 1992;52:562-5.

9. Negri E, La Vecchia C, Franceschi S, D'Avanzo B, Parazzini F. Vegetable and fruit consumption and cancer risk. Int J Cancer 1991;48: $350-4$. 
10. Wolk A, Gridley G, Niwa S, Lindblad P, McCredie M, Mellemgaard A, Mandel JS, Wahrendorf J, McLaughlin JK, Adami HO. International renal cell cancer study. VII. Role of diet. Int J Cancer 1996;65: 67-73.

11. Yuan JM, Gago-Dominguez M, Castelao JE, Hankin JH, Ross RK, $\mathrm{Yu}$ MC. Cruciferous vegetables in relation to renal cell carcinoma. In J Cancer 1998;77:211-6.

12. McLaughlin JK, Mandel JS, Blot WJ, Schuman LM, Mehl ES, Fraumeni JF, Jr. A population-based case-control study of renal cell carcinoma. J Natl Cancer Inst 1984;72:275-84.

13. Talamini R, Baron AE, Barra S, Bidoli E, La Vecchia C, Negri E, Serraino D, Franceschi S. A case-control study of risk factor for renal cell cancer in northern Italy. Cancer Causes Control 1990;1:125-31.

14. Yu MC, Mack TM, Hanisch R, Cicioni C, Henderson BE. Cigarette smoking, obesity, diuretic use, and coffee consumption as risk factors for renal cell carcinoma. J Natl Cancer Inst 1986;77:351-6.

15. Fraser GE, Phillips RL, Beeson WL. Hypertension, antihypertensive medication and risk of renal carcinoma in California Seventh-Day Adventists. Int J Epidemiol 1990;19:832-8.

16. Nicodemus KK, Sweeney C, Folsom AR. Evaluation of dietary, medical and lifestyle risk factors for incident kidney cancer in postmenopausal women. Int J Cancer 2004;108:115-21.

17. Rashidkhani B, Lindblad P, Wolk A. Fruits, vegetables and risk of renal cell carcinoma: a prospective study of Swedish women. Int J Cancer 2005; 113:451-5.

18. van Dijk BA, Schouten LJ, Kiemeney LA, Goldbohm RA, van den Brandt PA. Vegetable and fruit consumption and risk of renal cell carcinoma: results from the Netherlands cohort study. Int J Cancer 2005; 117:648-54.

19. Riboli E, Hunt KJ, Slimani N, Ferrari P, Norat T, Fahey M, Charrondiere UR, Hemon B, Casagrande C, Vignat J, Overvad K, Tjonneland A, et al. European Prospective Investigation into Cancer and Nutrition (EPIC): study populations and data collection. Public Health Nutr 2002;5:1113-24.

20. Riboli E, Kaaks R. The EPIC Project: rationale and study design. European Prospective Investigation into Cancer and Nutrition. Int $J$ Epidemiol 1997;26(Suppl 1):S6-14.

21. Margetts BM, Pietinen P. European Prospective Investigation into Cancer and Nutrition: validity studies on dietary assessment methods. Int J Epidemiol 1997;26(Suppl 1):S1-5.

22. Slimani N, Kaaks R, Ferrari P, Casagrande C, Clavel-Chapelon F, Lotze G, Kroke A, Trichopoulos D, Trichopoulou A, Lauria C, Bellegotti M, Ocke MC, et al. European Prospective Investigation into Cancer and Nutrition (EPIC) calibration study: rationale, design and population characteristics. Public Health Nutr 2002;5:1125-45.

23. Agudo A, Slimani N, Ocke MC, Naska A, Miller AB, Kroke A Bamia C, Karalis D, Vineis P, Palli D, Bueno-de-Mesquita HB, Peeters $\mathrm{PH}$, et al. Consumption of vegetables, fruit and other plant foods in the European Prospective Investigation into Cancer and Nutrition (EPIC) cohorts from 10 European countries. Public Health Nutr 2002 5:1179-96.

24. Bingham SA, Day NE, Luben R, Ferrari P, Slimani N, Norat T, Clavel-Chapelon F, Kesse E, Nieters A, Boeing H, Tjonneland A Overvad K, et al. Dietary fibre in food and protection against colorectal cancer in the European Prospective Investigation into Cancer and Nutrition (EPIC): an observational study. Lancet 2003;361:1496-501.

25. Bingham SA, Gill C, Welch A, Day K, Cassidy A, Khaw KT, Sneyd MJ, Key TJ, Roe L, Day NE. Comparison of dietary assessment methods in nutritional epidemiology: weighed records v. $24 \mathrm{~h}$ recalls, food-frequency questionnaires and estimated-diet records. Br J Nut 1994;72:619-43.

26. Kaaks R, Riboli E. Validation and calibration of dietary intake measurements in the EPIC project: methodological considerations. European Prospective Investigation into Cancer and Nutrition. Int J Epidemiol 1997;26(Suppl 1):S15-25.
27. van Gils $\mathrm{CH}$, Peeters PH, Bueno-de-Mesquita HB, Boshuizen HC, Lahmann PH, Clavel-Chapelon F, Thiebaut A, Kesse E, Sieri S, Palli D, Tumino R, Panico S, et al. Consumption of vegetables and fruits and risk of breast cancer. JAMA 2005;293:183-93.

28. Greenland S. Dose-response and trend analysis in epidemiology: alternatives to categorical analysis. Epidemiology 1995;6:356-65.

29. Rosenberg PS, Katki H, Swanson CA, Brown LM, Wacholder S, Hoover RN. Quantifying epidemiologic risk factors using non-parametric regression: model selection remains the greatest challenge. Stat Med 2003;22:3369-81.

30. Harrell FE, Jr, Lee KL, Pollock BG. Regression models in clinical studies: determining relationships between predictors and response. $\mathrm{J}$ Natl Cancer Inst 1988;80:1198-202.

31. Key TJ, Allen N, Appleby P, Overvad K, Tjonneland A, Miller A, Boeing H, Karalis D, Psaltopoulou T, Berrino F, Palli D, Panico S, et al. Fruits and vegetables and prostate cancer: no association among 1104 cases in a prospective study of 130544 men in the European Prospective Investigation into Cancer and Nutrition (EPIC). Int J Cancer 2004;109:119-24.

32. IARC Working Group on the Evaluation of Cancer Preventive Strategies M.Fruit and Vegetables IARC Handbooks of Cancer Prevention, vol.8. Lyon: IARC, 2003.

33. Steinmetz KA, Kushi LH, Bostick RM, Folsom AR, Potter JD. Vegetables, fruit, and colon cancer in the Iowa Women's Health Study. Am J Epidemiol 1994;139:1-15.

34. Slimani N, Ferrari P, Ocke M, Welch A, Boeing H, Liere M, Pala V, Amiano P, Lagiou A, Mattisson I, Stripp C, Engeset D, et al. Standardization of the 24-hour diet recall calibration method used in the European prospective investigation into cancer and nutrition (EPIC): general concepts and preliminary results. Eur J Clin Nutr 2000;54: 900-17.

35. Ferrari P, Kaaks R, Fahey MT, Slimani N, Day NE, Pera G, Boshuizen HC, Roddam A, Boeing H, Nagel G, Thiebaut A, Orfanos P, et al. Within- and between-cohort variation in measured macronutrient intakes, taking account of measurement errors, in the European Prospective Investigation into Cancer and Nutrition study. Am J Epidemiol 2004;160:814-22.

36. Kipnis V, Subar AF, Midthune D, Freedman LS, Ballard-Barbash R, Troiano RP, Bingham S, Schoeller DA, Schatzkin A, Carroll RJ. Structure of dietary measurement error: results of the OPEN biomarker study. Am J Epidemiol 2003;158:14-21; discussion 22-6.

37. Kipnis V, Midthune D, Freedman LS, Bingham S, Schatzkin A, Subar A, Carroll RJ. Empirical evidence of correlated biases in dietary assessment instruments and its implications. Am J Epidemiol 2001; 153:394-403.

38. Chow WH, Gridley G, Fraumeni JF, Jr, Jarvholm B. Obesity, hypertension, and the risk of kidney cancer in men. N Engl J Med 2000; 343:1305-11.

39. Lindblad P, Chow WH, Chan J, Bergstrom A, Wolk A, Gridley G, McLaughlin JK, Nyren O, Adami HO. The role of diabetes mellitus in the aetiology of renal cell cancer. Diabetologia 1999;42:107-12.

40. Prineas RJ, Folsom AR, Zhang ZM, Sellers TA, Potter J. Nutrition and other risk factors for renal cell carcinoma in postmenopausal women. Epidemiology 1997;8:31-6.

41. Handa K, Kreiger N. Diet patterns and the risk of renal cell carcinoma. Public Health Nutr 2002;5:757-67.

42. Maclure M, Willett W. A case-control study of diet and risk of renal adenocarcinoma. Epidemiology 1990;1:430-40.

43. Conaway CC, Yang YM, Chung FL. Isothiocyanates as cancer chemopreventive agents: their biological activities and metabolism in rodents and humans. Curr Drug Metab 2002;3:233-55.

44. Liu RH. Health benefits of fruit and vegetables are from additive and synergistic combinations of phytochemicals. Am J Clin Nutr 2003 ; 78(Suppl 3):S517-20. 